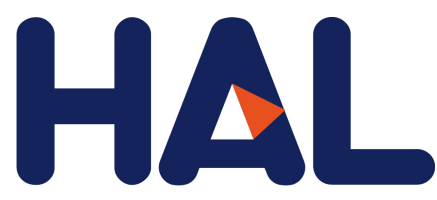

archives-ouvertes

\title{
Formation of stable strontium-rich amorphous calcium phosphate: Possible effects on bone mineral
}

Camila Bussola Tovani, Alexandre Gloter, Thierry Azaïs, Mohamed Selmane, Ana Ramos, Nadine Nassif

\section{- To cite this version:}

Camila Bussola Tovani, Alexandre Gloter, Thierry Azaïs, Mohamed Selmane, Ana Ramos, et al.. Formation of stable strontium-rich amorphous calcium phosphate: Possible effects on bone mineral. Acta Biomaterialia, Elsevier, 2019, 92, pp.315-324. 10.1016/j.actbio.2019.05.036 . hal-02264838

\section{HAL Id: hal-02264838 \\ https://hal.sorbonne-universite.fr/hal-02264838}

Submitted on 22 Aug 2019

HAL is a multi-disciplinary open access archive for the deposit and dissemination of scientific research documents, whether they are published or not. The documents may come from teaching and research institutions in France or abroad, or from public or private research centers.
L'archive ouverte pluridisciplinaire HAL, est destinée au dépôt et à la diffusion de documents scientifiques de niveau recherche, publiés ou non, émanant des établissements d'enseignement et de recherche français ou étrangers, des laboratoires publics ou privés. 
Full length article

\title{
Formation of stable strontium-rich amorphous calcium phosphate: Possible effects on bone mineral
}

\author{
Camila Bussola Tovani ${ }^{\mathrm{a}, \mathrm{d}, *}$, Alexandre Gloter ${ }^{\mathrm{b}}$, Thierry Azaïs ${ }^{\mathrm{a}}$, Mohamed Selmane ${ }^{\mathrm{c}}$, Ana P. Ramos ${ }^{\mathrm{d}}$, \\ Nadine Nassif ${ }^{a, *}$ \\ a Sorbonne Université, CNRS, Collège de France, Laboratoire Chimie de la Matière Condensée de Paris, 4 Place Jussieu, F-75005 Paris, France \\ ${ }^{\mathrm{b}}$ Université Paris Sud, Laboratoire de Physique des Solides, CNRS UMR 8502, F-91405 Orsay, France \\ ' Institut des Matériaux de Paris Centre, IMPC, Univ Paris 06, Collège de France, 11 place Marcelin Berthelot, F-75231 Paris, France \\ ${ }^{\mathrm{d}}$ Departamento de Química, Faculdade de Filosofia, Ciências e Letras de Ribeirão Preto, Universidade de São Paulo, Ribeirão Preto 14040-901, SP, Brazil
}

\section{A R T I C L E I N F O}

\section{Article history:}

Received 27 February 2019

Received in revised form 21 April 2019

Accepted 13 May 2019

Available online 22 May 2019

\begin{abstract}
A B S T R A C T
Bone, tooth enamel, and dentin accumulate $\mathrm{Sr}^{2+}$, a natural trace element in the human body. $\mathrm{Sr}^{2+} \mathrm{comes}$ from dietary and environmental sources and is thought to play a key role in osteoporosis treatments. However, the underlying impacts of $\mathrm{Sr}^{2+}$ on bone mineralization remain unclear and the use of synthetic apatites (which are structurally different from bone mineral) and non-physiological conditions have led to contradictory results. Here, we report on the formation of a new $\mathrm{Sr}^{2+}$-rich and stable amorphous cal-

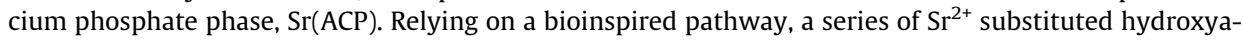
patite (HA) that combines the major bone mineral features is depicted as model to investigate how this phase forms and $\mathrm{Sr}^{2+}$ affects bone. In addition, by means of a comprehensive investigation the biomineralization pathway of $\mathrm{Sr}^{2+}$ bearing $\mathrm{HA}$ is described showing that not more than 10 at\% of $\mathrm{Sr}^{2+}$, i.e. a physiological limit incorporated in bone, can be incorporated into HA without phase segregation. A combination of ${ }^{31} \mathrm{P}$ and ${ }^{1} \mathrm{H}$ solid state NMR, energy electron loss spectromicroscopy, transmission electron microscopy, electron diffraction, and Raman spectroscopy shows that $\mathrm{Sr}^{2+}$ introduces disorder in the HA culminating with the unexpected $\mathrm{Sr}(\mathrm{ACP})$, which co-exists with the HA under physiological conditions. These results suggest that heterogeneous $\mathrm{Sr}^{2+}$ distribution in bone is associated with regions of low structural organization. Going further, such observations give clues from the physicochemical standpoint to understand the defects in bone formation induced by high $\mathrm{Sr}^{2+}$ doses.
\end{abstract}

\section{Statement of Significance}

Understanding the role played by $\mathrm{Sr}^{2+}$ has a relevant impact in physiological biomineralization and provides insights for its use as osteoporosis treatments. Previous studies inspired by the bone remodelling pathway led to the formation of biomimetic HA in terms of composition, structures and properties in water. Herein, by investigating different atomic percentage of $\mathrm{Sr}^{2+}$ related to $\mathrm{Ca}^{2+}$ in the synthesis, we demonstrate that $10 \%$ of $\mathrm{Sr}^{2+}$ is the critical loads into the biomimetic HA phase; similarly to bone. Unexpectedly, using higher amount leads to the formation of a stable $\mathrm{Sr}^{2+}$-rich amorphous calcium phosphate phase that may high-dose related pathologies. Our results provide further understanding of the different ways $\mathrm{Sr}^{2+}$ impacts bone.
* Corresponding authors at: Sorbonne Université, CNRS, Collège de France, Laboratoire Chimie de la Matière Condensée de Paris, 4 Place Jussieu, F-75005 Paris, France (C. Bussola Tovani and N. Nassif).

E-mail addresses: camilabussola@usp.br, nadine.nassif@sorbonne-universite.fr (C. Bussola Tovani)

\section{Introduction}

Bone is a complex tissue that undergoes continuous remodeling through action of osteoblasts and osteoclasts [1]. The remodeling cycle regulates the bone architecture and mechanical properties by repairing small damages and removing old tissue [2]. Cells produce growth factors, cytokines, and non-collagenous proteins, which regulate the remodeling cycle [3]. Trace elements also play a role in bone mineral phase remodeling [4]. Among such 
elements, strontium has been shown to exert a dual effect on the bone regeneration dynamics: it reduces bone resorption and increases bone formation [5]. $\mathrm{Sr}^{2+}$ preferentially accumulates in the bone tissue (99\% of the total $\mathrm{Sr}^{2+}$ amount in the body): $\mathrm{Sr}^{2+}$ and $\mathrm{Ca}^{2+}$ have similar charge-to-size ratio, so the former ion replaces the latter ion in apatite[6]. A maximum of $10-12 \%$ of $\mathrm{Sr}^{2+}$ is found in biological apatite after its administration [7,8].

$\mathrm{Sr}^{2+}$ can also substitute $\mathrm{Ca}^{2+}$ in the crystalline structure of other biominerals such as carbonates $[9,10]$.

Although $\mathrm{Sr}^{2+}$ is a non-essential trace element found in the human body and behaves similarly to $\mathrm{Ca}^{2+}$ and $\mathrm{Mg}^{2+}$ in physiological environment [11], $\mathrm{Sr}^{2+}$ administration in the form of strontium ranelate has a dual effect on bone metabolism: it stimulates osteoblast proliferation while decreasing osteoclast activity, thereby increasing bone mineral density. Such effect has not been observed for other divalent cations. On the basis of this dual effect, several $\mathrm{Sr}^{2+}$-based medicines [12-14] and biomaterials [15,16] have been developed to treat osteoporosis, a bone disease that affects hundreds of millions of people worldwide [17,18]. However, $\mathrm{Sr}^{2+}$ administration has a dose-dependent impact on bone formation [19] and high $\mathrm{Sr}^{2+}$ doses have been associated with the development of skeletal diseases like osteomalacia in rats with renal failure $[20,21]$

$\mathrm{Sr}^{2+}$ incorporation into bone is heterogeneous. Higher $\mathrm{Sr}^{2+}$ concentrations occur in newly formed bone and are related to locally higher metabolism [14]. For example, $\mathrm{Sr}^{2+}$ is exclusively incorporated into new bone of patients treated with strontium ranelate [22]. Besides its impact at the cellular level, one question remains: how does $\mathrm{Sr}^{2+}$ affect the mineralized bone matrix? In an attempt to understand how $\mathrm{Sr}^{2+}$ influences bone apatite at the crystalline structure level, several syntheses of $\mathrm{Sr}^{2+}$-substituted HA have been described [23-26]. Nevertheless, bone mineral and synthetic HA have distinct features, which limit the correlation between in vitro and in vivo results.

Bone apatite, formed under physiological conditions, bears a hydrated amorphous shell and a core consisting of nanometric crystals with plate-like morphology [27] and preferential crystallographic orientation along the $c$ axis [28]. Furthermore, bone apatite is nonstoichiometric and can host different ions in its crystalline lattice and/or outer layer [29]. The bone apatite structural features are strongly related to ion substitutions, especially $\mathrm{PO}_{4}^{3-}$ and $\mathrm{OH}^{-}$ replacement with $\mathrm{CO}_{3}^{2-}$, and the presence of water [30-32].

Reproducing such bone mineral features in vitro remains a challenge and is vitally important for better comprehension of in vivo phenomena. Different attempts have been made to obtain biomimetic apatite. However, the non-physiological conditions used during the synthesis include high temperature [33], microwave radiation [34], high pressure [35], solid-state diffusion [36], organic solvents [37], and stabilizing agents [38], which may give products with distinct crystallinity, surface area, crystal size, and composition as compared to bioapatite. Moreover, the experimental conditions may promote kinetic and thermodynamic controls over the reaction and select different phases and polymorphs [30]. Indeed, isomorphic $\mathrm{Ca}^{2+}$ substitution for $\mathrm{Sr}^{2+}$ in the apatite crystalline structure has been reported up to $100 \%$ of substitution $[23,39]$, but the formation of such strontium apatite has not been described in biological systems.

Heterogeneous $\mathrm{Sr}^{2+}$ distribution at atomic scale is another factor that prevents $\mathrm{Sr}^{2+}$ impact on bone apatite from being evaluated. In this sense, controlled in vitro bone-like systems are necessary to mimic this event and to provide insights in this regard.

To address these shortcomings, a simple and versatile procedure to study $\mathrm{Sr}^{2+}$ incorporation into bone mineral is described. The strategy consists in using bioinspired conditions described in bone remodeling process [40], i.e. water at room pressure and temperature and initial low $\mathrm{pH}$, to mimic the environment at the min- eralizing front. The influence of $\mathrm{Sr}^{2+}$ on the formation of biomimetic apatite was investigated by substituting $\mathrm{Ca}^{2+}$ ranging from 0 up to 100 at\%. Using a combination of energy electron loss spectroscopy (EELS), ${ }^{31} \mathrm{P}$ solid state nuclear magnetic resonance spectroscopy (NMR), Raman spectroscopy, X-ray diffraction (XRD), transmission electron microscopy (TEM), and selected area electron diffraction (SAED), the resulting phosphate phases were characterized providing clues to understand the presence of bone defects upon high $\mathrm{Sr}^{2+}$ doses.

\section{Experimental}

\subsection{Synthesis of biomimetic apatite containing different amount of $\mathrm{Sr}^{2+}$}

Biomimetic apatite was synthesized on the basis of an approach developed by Nassif et al. [31]; $\mathrm{NH}_{3}(\mathrm{~g})$ diffusion was used at ambient temperature. Briefly, stock $\mathrm{CaCl}_{2}(110 \mathrm{mM}), \mathrm{SrCl}_{2}(110 \mathrm{mM})$, $\mathrm{NaH}_{2} \mathrm{PO}_{4}(33 \mathrm{mM})$, and $\mathrm{NaHCO}_{3}(33 \mathrm{mM})$ solutions were prepared by dissolving $\mathrm{CaCl}_{2} \cdot 2 \mathrm{H}_{2} \mathrm{O}$ (Sigma), $\mathrm{SrCl}_{2} \cdot 6 \mathrm{H}_{2} \mathrm{O}$ (Sigma), $\mathrm{NaHCO}_{3}$ (Sigma), and $\mathrm{NaH}_{2} \mathrm{PO}_{4}$ (Sigma) in aqueous acetic acid $(500 \mathrm{mM})$ solution. Mixtures containing different $\mathrm{Sr}^{2+}$ molar percentages (namely $0,5,10,25,50,75$, and $100 \%$ ) in relation to the total number of mols of divalent cations $\left(\mathrm{Ca}^{2+}+\mathrm{Sr}^{2+}\right)$ were prepared. The (Ca $+\mathrm{Sr}) /(\mathrm{P}+\mathrm{C})$ ratio was kept constant and equal to 1.67 and $\mathrm{pH} \sim 3.5$. Two flasks ( $35 \mathrm{~mL}, \mathrm{~h}=50 \mathrm{~mm}$ ) containing these solutions $(20 \mathrm{~mL}$ ) and covered with perforated (four holes) parafilm were placed in a closed desiccator. A third flask containing fresh aqueous ammonia solution ( $30 \mathrm{wt} \%, 8 \mathrm{~mL}$ ) was placed in the desiccator. $\mathrm{NH}_{3(\mathrm{~g})}$ diffusion into the flasks slowly increases the solution $\mathrm{pH}$ and triggered $\mathrm{Sr}-\mathrm{Ca}$ phosphate precipitation. After reaction for one or six days ( $\mathrm{pH} \sim 11$ ), the solids were washed with distilled water and then ethanol, to remove soluble salts, and centrifuged (6000 rpm, $10 \mathrm{~min}$ ). The recovered powders were dried at $37^{\circ} \mathrm{C}$ for three days before characterization.

\subsection{Samples characterization}

X-ray diffraction analysis was carried out on a Bruker D8 X-ray diffractometer operating in the reflection mode with $\mathrm{CuK} \alpha$ radiation, beam voltage of $40 \mathrm{kV}$, and beam current of $40 \mathrm{~mA}$. The data were collected in the $2 \theta$ range of $5-80^{\circ}$, with steps of $0.01^{\circ}$ and a counting time of $9 \mathrm{~s}$. The interplanar distances (d values) were estimated in the direction of the plane (002) in the $2 \theta$ range of 25.7$25.9^{\circ}$. The coherent domain length was estimated in the direction of the planes (111) and (021) in the $2 \theta$ range of $25-27^{\circ}$, according to the Scherrer equation. This length was also estimated by HRTEM. The crystal lattice parameters were calculated in the software check-cell by using the shift of the diffraction peaks. Fourier-transform infrared spectra with attenuated total reflectance (ATR-FTIR) were obtained on a Perkin Elmer Spectrum One spectrophotometer in the range of $4100-550 \mathrm{~cm}^{-1}$ with a resolution of $1 \mathrm{~cm}^{-1}$. Raman spectra were recorded in the range of $1200-300 \mathrm{~cm}^{-1}$ on a spectrophotometer Kaiser Optical Systems with a diode laser operating at $\lambda=785 \mathrm{~nm}$ as excitation source. Thermogravimetric analysis (TGA) experiments were performed on a thermo-microbalance instrument (NETZSCH STA409PC). The measurements were performed from room temperature to $100^{\circ} \mathrm{C}$ in air atmosphere with a heating rate of $5^{\circ} \mathrm{C} / \mathrm{min}$. Scanning electron microscopy (SEM) images and energy dispersive spectroscopy (EDS) were conducted on a microscope Hitachi S-3400N under accelerating voltage of $10 \mathrm{kV}$. To this end, samples were covered with a $10 \mathrm{~nm}$ gold layer. EDS was performed using an Oxford instruments X-MAX detector $\left(20 \mathrm{~mm}^{2}\right)$. To this end the samples were coated with a $10-\mathrm{nm}$ carbon layer. A transmission electron 
microscope (TEM JEOL 2011) operating at $100 \mathrm{keV}$ was used to obtain the TEM and high-resolution (HRTEM) images and the selected area electron diffraction patterns (SAED). EDS mapping of the elements $\mathrm{Ca}, \mathrm{Sr}, \mathrm{O}$ and $\mathrm{P}$ was performed on a single particle by using a TEM microscope FEI TECNAI G2 F20 HRTEM operating at $200 \mathrm{kV}$. To this end, the samples were dispersed in ethanol and some drops were deposited on a lacey carbon film on copper grid. EELS spectra were acquired in a Nion STEM microscope at $200 \mathrm{keV}$. ${ }^{1} \mathrm{H}$ and ${ }^{31} \mathrm{P}$ solid-state NMR experiments were conducted on an Avance 300 Bruker spectrometer operating at $v\left({ }^{1} \mathrm{H}\right)=300.13 \mathrm{MHz}$ and $v\left({ }^{31} \mathrm{P}\right)=121.5 \mathrm{MHz}$. The powders were packed in $4 \mathrm{~mm}$ zirconia rotors and spun at $14 \mathrm{kHz} .{ }^{31} \mathrm{P}$ direct aquisition spectra were recorded in quantitative conditions used a recycle delay (RD) of $60 \mathrm{~s}$ and a $30^{\circ}$ pulse, the number of scans (NS) were set to 80 . The $2 \mathrm{D}{ }^{1} \mathrm{H}^{3}{ }^{31} \mathrm{P}$ HetCor spectra were recorded using the following parameters $R D=2 \mathrm{~s}$; contact time $t_{C P}=1 \mathrm{~ms}$, NS $=32-80$ for each 40-120 $t_{1}$ increments depending on the sample. The Double CP ${ }^{1} \mathrm{H} \rightarrow{ }^{31} \mathrm{P} \rightarrow{ }^{1} \mathrm{H}$ MAS NMR experiment is described elsewhere in the literature [41] and the following parameters were used: $R D=2$, $\mathrm{t}_{\mathrm{CP}} 1=\mathrm{t}_{\mathrm{CP}} 2=1 \mathrm{~ms}$, NS $=2000-3000$ depending on the sample. The chemical shifts were referenced to $\mathrm{H}_{3} \mathrm{PO}_{4} 85 \%$ wt for ${ }^{31} \mathrm{P}(0 \mathrm{ppm})$ and adamantane for ${ }^{1} \mathrm{H}(0 \mathrm{ppm})$.

\section{Results and discussion}

\section{1. $\mathrm{Ca}^{2+}$ substitution for $\mathrm{Sr}^{2+}$ in biomimetic $\mathrm{HA}$ leads to $\mathrm{Sr}(\mathrm{ACP})$ formation}

Our study started with bioinspired HA synthesis, during which we employed simple chemical conditions that also occur in vivo. The vapor diffusion approach allowed us to control $\mathrm{pH}$ increase through $\mathrm{NH}_{3}(\mathrm{~g})$ dissolution in the precursor acidic solution containing the $\mathrm{PO}_{4}^{3-}, \mathrm{CO}_{3}^{2-}, \mathrm{Sr}^{2+}$, and $\mathrm{Ca}^{2+}$ ions, thereby producing nanocrystalline and carbonated apatite that resembled apatite found in bone and teeth [31]. Moreover, the initial low pH enabled us to study $\mathrm{Sr}^{2+}$ incorporation into HA in conditions that mimicked the conditions found in the acidic extracellular environment where osteoclasts act during bone remodeling [42]. Table S1 summarizes
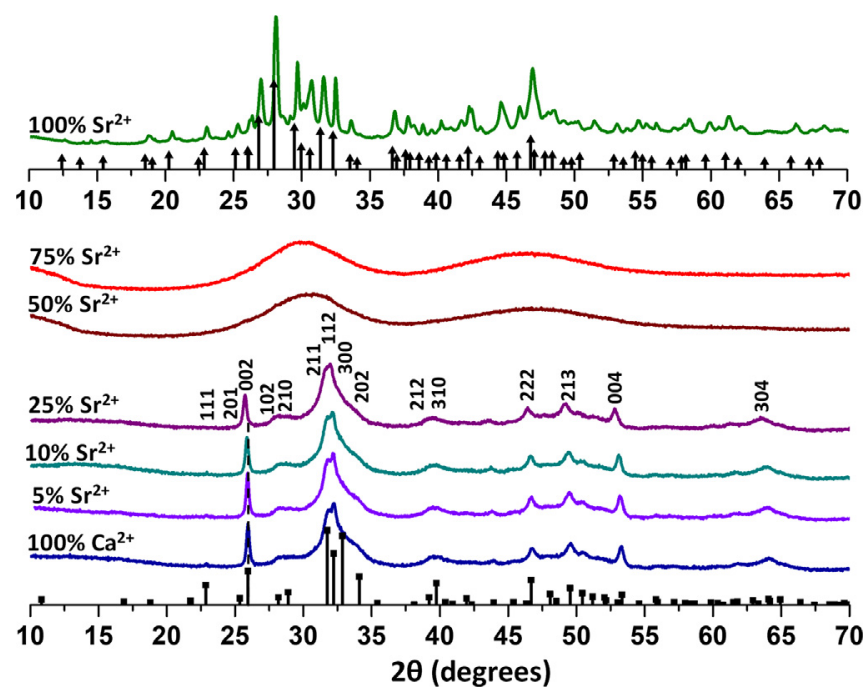

Fig. 1. XRD patterns for the series of samples $0-100 \% \mathrm{Sr}^{2+}$ after six days of reaction. The peaks of the $0-25 \% \mathrm{Sr}^{2+}$ samples are indexed with the hydroxyapatite structure (JCPDS 00-009-0432). $\mathrm{Sr}(\mathrm{ACP})$ is observed upon increasing $\mathrm{Sr}^{2+}$ content in the samples $\left(50-75 \% \mathrm{Sr}^{2+}\right)$. The peaks of $100 \% \mathrm{Sr}^{2+}$ sample are indexed with the Collin's salt structure (JCPDS 00-019-1287). For the samples with apatitic structure (0-25\% $\mathrm{Sr}^{2+}$ ), the dashed line indicates displacement of the (002) reflection to lower $2 \theta$ values upon increasing $\mathrm{Sr}^{2+}$ content. the $\% \mathrm{Sr}^{2+}$ incorporated into the final solids as determined by SEMEDS. $\mathrm{Sr}^{2+}$ incorporation was proportional to the $\mathrm{Sr}^{2+}$ amount in the starting solutions. XRD, ATR-FTR, SEM, TEM and Raman spectroscopy were combined to follow the $\mathrm{Sr}^{2+}$ impact on the HA structure. The diffraction peaks (Fig. 1 ) reveal that the series of samples $0-25 \% \mathrm{Sr}^{2+}$ correspond to hexagonal HA (space group $P 63 / \mathrm{m}$ ). The XRD patterns of the samples exhibit broad peaks, related to small crystallite size and to the presence of $\mathrm{CO}_{3}^{2-}$ ions, which are a source of structural disorder in bone [28] (see next sections). Moreover, the higher intensity of the 002 peak in relation to the pattern suggests preferential orientation and larger coherent domain along the $c$ axis. Such features confirm structural similarity between the bone mineral and the HA model adopted in this study, which is crucial to understand the in vitro results and in vivo events and to correlate them. Furthermore, the $(002)$ Bragg reflections in the XRD patterns (Fig. S1) of the samples $0-25 \% \mathrm{Sr}^{2+}$ shifted linearly to lower $2 \theta$ values with increasing $\mathrm{Sr}^{2+}$ percentage, indicating that the interplanar distances and hence the lattice parameters augmented. Indeed, estimation of the interplanar distance (Table 1) along the 002 plane and the lattice constants demonstrate that $\mathrm{Ca}^{2+}$ replacement with $\mathrm{Sr}^{2+}$ in apatite expands the unit cell, which is in agreement with the larger $\mathrm{Sr}^{2+}$ ionic radius. Even though $\mathrm{Ca}^{2+}$ replacement with $\mathrm{Sr}^{2+}$ provokes crystal strain, the hexagonal symmetry is maintained up to the $25 \% \mathrm{Sr}^{2+}$ sample. Surprisingly, the $50 \% \mathrm{Sr}^{2+}$ and $75 \% \mathrm{Sr}^{2+}$ samples do not display Bragg reflections, indicating the precipitation of an amorphous phase and inhibition of $\mathrm{HA}$ formation. In the case of the $100 \% \mathrm{Sr}^{2+}$ sample, a well crystallized phase indexed as Collin's salt $\left(\mathrm{Sr}_{6} \mathrm{H}_{3}\left(\mathrm{PO}_{4}\right)_{5} .2 \mathrm{H}_{2} \mathrm{O}\right)$ arises instead of the fully $\mathrm{Sr}^{2+}$-substituted HA.

The Raman spectra of the apatitic samples, $5 \% \mathrm{Sr}^{2+}, 10 \% \mathrm{Sr}^{2+}$ and $25 \% \mathrm{Sr}^{2+}$, (Fig. S2) evidence a linear wavenumber downshift of the $\mathrm{PO}_{4}^{3-}$ band (Fig. S2c) as compared to the spectrum of pure $\mathrm{HA}(0 \%$ $\mathrm{Sr}^{2+}$ ). Although total $\mathrm{Sr}^{2+}$ incorporation into the HA hydrated surface layer could have occurred, these results corroborate heteroionic $\mathrm{Ca}^{2+}$ substitution for $\mathrm{Sr}^{2+}$. With respect to structural changes, $\mathrm{PO}_{4}^{3-}$ band broadening with $\mathrm{Sr}^{2+}$ addition suggests that the presence of $\mathrm{Sr}^{2+}$ in the HA lattice causes progressive crystalline disorder, which agrees with XRD observations. This trend is characterized by linear correlation between the full width half maximum (FWHM) values and the $\mathrm{Sr}^{2+}$ content in the samples (Fig. S2d). Such effects have been described in synthetic systems $[23,39]$, as well as in minerals arising in cell culture during $\mathrm{Sr}^{2+}$ treatments [43]. In fact, $\mathrm{Sr}^{2+}$ uptake by minerals synthesized by osteoblasts has been shown to occur in a dose-dependent manner and to be accompanied by a linear increase in cell parameters [44]. Up to $25 \% \mathrm{Ca}^{2+}$ substitution for $\mathrm{Sr}^{2+}$ in the lattice of synthetic HA has been reported to cause structural disorder, whereas higher $\mathrm{Sr}^{2+}$ concentrations have been shown to increase HA crystallinity $[23,24]$. As revealed by in vivo studies, small changes in the structural properties of the $5 \% \mathrm{Sr}^{2+}$ sample can be related to no marked effects in the bone mineral density of rats treated with low $\mathrm{Sr}^{2+}$ dosages [45]. According to previous reports showing that the bone mineral strength is inversely related to its crystallinity [46,47], the crystallinity reduction observed for $\mathrm{Sr}^{2+}$ concentrations of up to $25 \%$ may be related to increased bone rigidity in osteoporotic patients. In accordance with the XRD results, the ATR-FTIR spectra of the $0-25 \% \mathrm{Sr}^{2+}$ samples display sharper bands ascribed to the $\mathrm{PO}_{4}^{3-}$ vibration modes, whilst the $50 \% \mathrm{Sr}^{2+}$ and $75 \% \mathrm{Sr}^{2+}$ samples exhibit a marked broad line in agreement with their amorphous nature (Fig. 2a). The band observed near $3330 \mathrm{~cm}^{-1}$ is related to $\mathrm{OH}$ stretch vibration of hydroxide groups and adsorbed water. This band and the one at $1600 \mathrm{~cm}^{-1}$, which is related to the bending mode of water molecule, are relatively more intense for the $50 \%$ $\mathrm{Sr}^{2+}$ and $75 \% \mathrm{Sr}^{2+}$ samples. This is in agreement with the higher degree of hydration in amorphous phosphate phases [28]. Indeed, TGA (Fig. S3) revealed a higher content of water in the $50 \% \mathrm{Sr}^{2+}$ 
Table 1

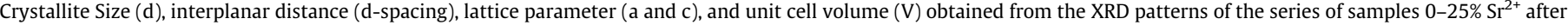
six days of reaction.

\begin{tabular}{|c|c|c|c|c|c|}
\hline Sample & $\mathrm{d}(\mathrm{nm})$ & d-spacing $(\AA)$ & $a(\AA)$ & $\mathrm{c}(\AA)$ & $\mathrm{V}\left(\AA^{3}\right)$ \\
\hline $0 \% \mathrm{Sr}^{2+}$ & $32.31 \pm 0.27$ & $3.437 \pm 0.003$ & $9.432 \pm 0.005$ & $6.874 \pm 0.005$ & 529.60 \\
\hline $5 \% \mathrm{Sr}^{2+}$ & $31.43 \pm 0.29$ & $3.439 \pm 0.002$ & $9.432 \pm 0.005$ & $6.877 \pm 0.005$ & 529.83 \\
\hline $10 \% \mathrm{Sr}^{2+}$ & $30.54 \pm 0.24$ & $3.444 \pm 0.002$ & $9.434 \pm 0.005$ & $6.888 \pm 0.003$ & 530.89 \\
\hline $25 \% \mathrm{Sr}^{2+}$ & $27.61 \pm 0.21$ & $3.458 \pm 0.003$ & $9.466 \pm 0.005$ & $6.917 \pm 0.003$ & 536.73 \\
\hline
\end{tabular}
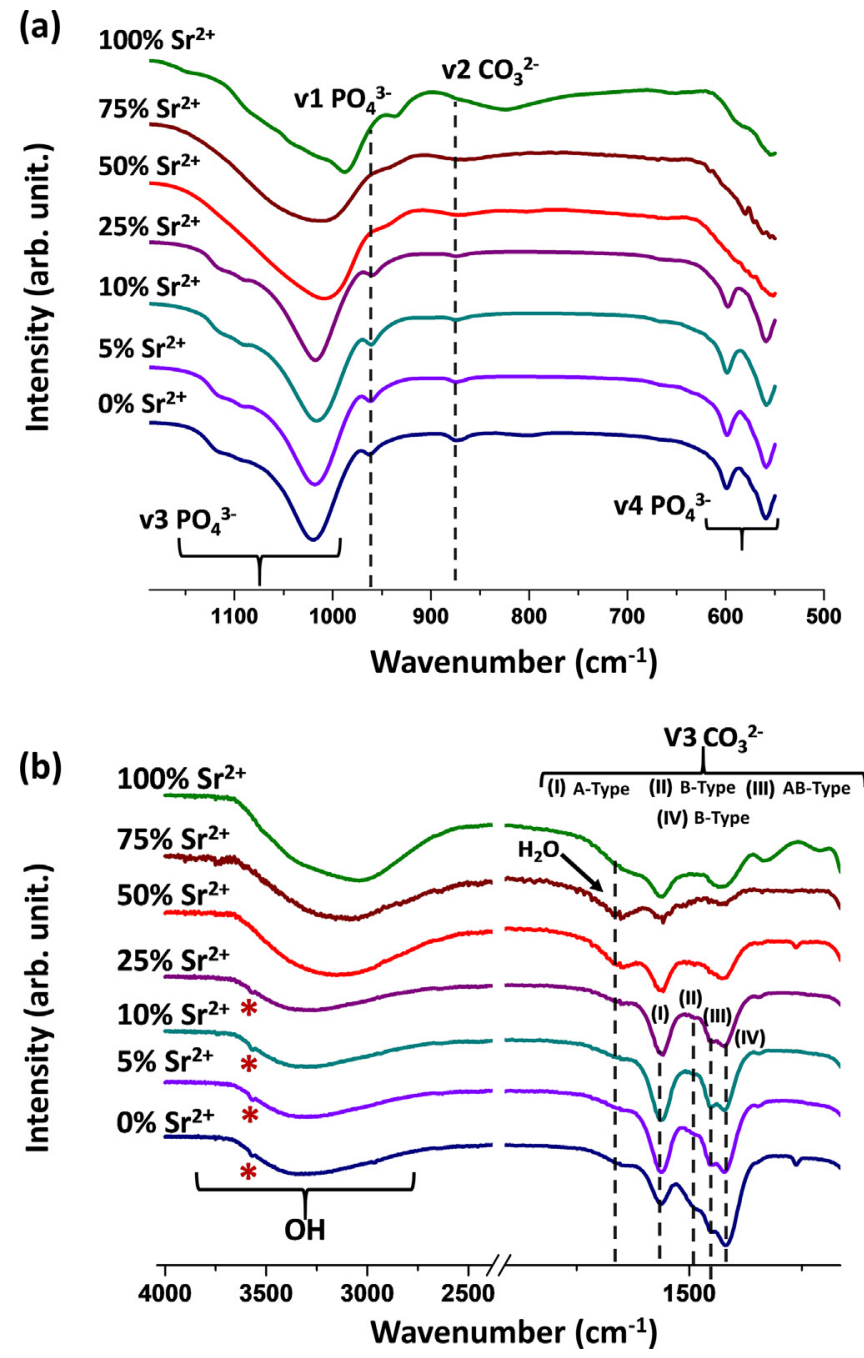

Fig. 2. ATR-FTIR spectra of the series of samples $0-75 \% \mathrm{Sr}^{2+}$ after six days of reaction displaying typical bands of (a) $\mathrm{PO}_{4}^{3-}\left(v_{1}, v_{3}\right.$ and $v_{4}$ vibrational modes) and $\mathrm{CO}_{3}^{2-}\left(v_{2}\right.$ vibrational mode) and (b) $\mathrm{CO}_{3}^{2-}$ ( $v_{3}$ vibrational mode), $\mathrm{OH}^{-}$groups and $\mathrm{H}_{2} \mathrm{O}$ molecules.

and $75 \% \mathrm{Sr}^{2+}$ (18.9 wt\% and $16.6 \mathrm{wt} \%$, respectively) compared to the $0 \% \mathrm{Sr}^{2+}$ sample (9.8 wt\%). Additionally, a weak band attributed to structural $\mathrm{OH}$ vibration (assigned by ${ }^{*}$ ) is observed in the spectra of the series of samples $0-25 \% \mathrm{Sr}^{2+}$ as a result of hydroxyl ions in crystalline apatitic environments [48]. The presence of typical $\mathrm{CO}_{3}^{2-}$ bands in the regions of 870 and $1360-1580 \mathrm{~cm}^{-1}$ ( $r_{2}$ symmetric and $v_{3}$ asymmetric stretching respectively) (Fig. 2) confirms that the samples have carbonated nature and resemble biological apatite found in bone tissue and tooth enamel [29]. Notably, such bands are less intense in the spectra of the amorphous particles. $\mathrm{CO}_{3}^{2-}$ ions can be hosted in the disordered hydrated layer of bone apatite or in its crystalline core by lattice substitution of $\mathrm{PO}_{4}^{3-}$ ions (B-type), $\mathrm{OH}^{-}$ions (A-type) or both (AB-type) [49]. Further analysis of the $\mathrm{CO}_{3}^{2-}$ bands reveals less intense $v_{3}$ bands, related to B-type substitution, and a more intense $v_{3}$ band, related to A-type substitution, as indicated by the dashed lines (Fig. 2b). Deconvolution of the $\mathrm{CO}_{3}^{2-} v_{2}$ band reveals an increase of $\sim 22 \%$ of type A substitution in the $\mathrm{Sr}^{2+}$ containing samples in relation to the $0 \% \mathrm{Sr}^{2+}$ sample [50]. A-type substitution is a mechanism that facilitates $\mathrm{CO}_{3}^{2-}$ charge balance and spatial accommodation [51]. In this sense, the present data indicate that $\mathrm{Ca}^{2+}$ substitution for $\mathrm{Sr}^{2+}$ may influence charge distribution in $\mathrm{HA}$, which in turn affects the $\mathrm{CO}_{3}^{2-}$ substitution site. Furthermore, in biological apatite, such substitution influences the local disorder and promotes formation of an amorphous layer in the bone mineral [28]. Although bone aging and biological activity are known to affect the $\mathrm{CO}_{3}^{2-}$ amount [52], this relationship is not yet completely understood. In this context, besides the impact on crystalline properties, the influence on $\mathrm{CO}_{3}^{2-}$ substitution suggests further effects of $\mathrm{Sr}^{2+}$ in bone mineral.

Typical spherulitic aggregates are observed in the SEM images of the series of samples with apatite structure (Fig. 3a-d). The samples with less than $50 \%$ of $\mathrm{Sr}^{2+}$ do not differ significantly in terms of morphology. The $50 \% \mathrm{Sr}^{2+}$ and $75 \% \mathrm{Sr}^{2+}$ samples (characterized as amorphous in the discussion above) display regular and spherical morphology (Fig. 3e, f). As for the sample identified as Collin's salt, it has plate-like morphology (Fig. 3g). In agreement with the wavy background present in diffractogram of the latter sample (Fig. 1), amorphous particles are also observed in its SEM images (Fig. 3h). The morphological differences evidenced by SEM attest to the structural/compositional changes described previously herein. TEM performed on the series of samples $0-25 \% \mathrm{Sr}^{2+}$ reveals that the spherulites observed by SEM are formed by the aggregation of nanometric crystals with plate-like morphology with thickness of 3-6 nm (Fig. S4a-d), similar to that one found in bone [31,53]. Notably, SAEDs (Fig. S4e, f) confirm the (002) planes preferential radial orientation in the spherulitic HA particles. Although XRD identifies HA as the major phase in the $25 \% \mathrm{Sr}^{2+}$ sample, TEM reveals the presence of a low amount of smaller spherical particles characterized as amorphous with SAED pattern (Fig. S5). Elementary TEM mapping results (Fig. S6) show that the elements $\mathrm{Ca}, \mathrm{Sr}$, $\mathrm{P}$, and $\mathrm{O}$ are homogeneously distributed in the HA and amorphous particles, confirming that $\mathrm{Sr}^{2+}$ and $\mathrm{Ca}^{2+}$ are incorporated into both types of particles. Such result contrasts with findings reported for synthetic HA, for which isomorphic $\mathrm{Ca}^{2+}$ substitution for $\mathrm{Sr}^{2+}$ is described up to $100 \%$ of $\mathrm{Sr}^{2+}[23,25,26,39]$. Regardless of the administered dose, bone mineral has been shown to incorporate a maximum of $12.3 \% \mathrm{Sr}^{2+}$ in the lattice; any excess $\mathrm{Sr}^{2+}$ is loaded on the bone surface by adsorption and ion exchange [54,22].

The presence of such amorphous phase can be seen as evidence of $\mathrm{Sr}^{2+}$ physicochemical interference on apatite formation and could account for the adverse effects of the administration of high $\mathrm{Sr}^{2+}$ doses observed in vivo [55] and in cell cultures in vitro [19]. In fact, high $\mathrm{Sr}^{2+}$ doses have been reported to induce mineralization defect in rats with normal renal functions [55] and osteomalacia (a bone disease caused by defective mineralization) in rats with chronic renal failures [56]. Collin's salt formation is in line with the presence of insoluble salts and rickets in animals with high dietary $\mathrm{Sr}^{2+}$ [57]. Still in this regard, rather than $\mathrm{Sr}^{2+}-\mathrm{HA}$, a mixture of minerals containing $\mathrm{SrHPO}_{4}$ has been reported to arise in the 

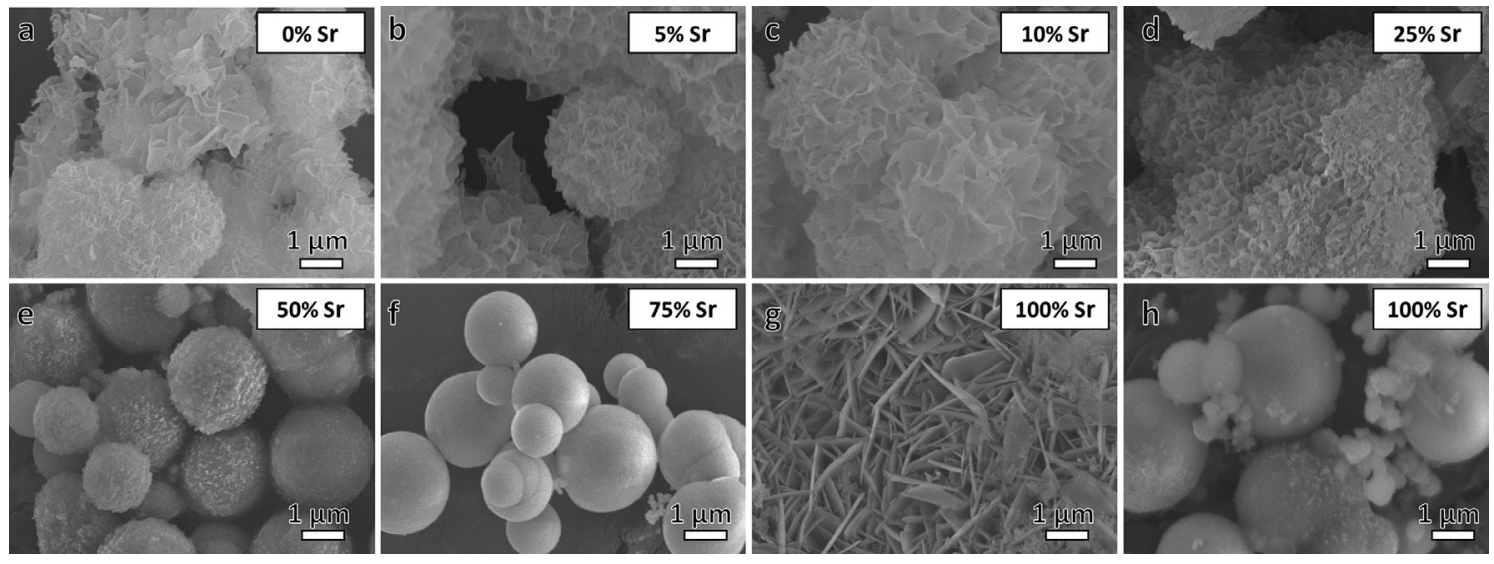

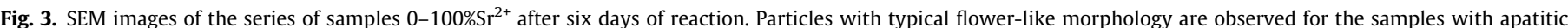

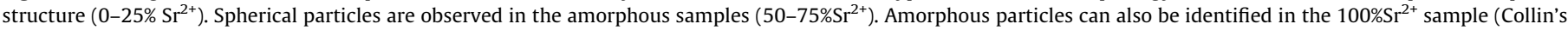
salt structure).

presence of high $\mathrm{Sr}^{2+}$ concentrations in the mineralization medium containing matrix vesicles [58]. Similarly, different $\mathrm{Sr}^{2+}$-phosphate phases together with amorphous precipitate have been found in mineralized cell cultures exposed to high $\mathrm{Sr}^{2+}$ doses [44]. Interestingly, these outcomes highlight the different impact $\mathrm{Sr}^{2+}$ has on biological apatite and synthetic HA. Such differences may be due to the use of non-physiological conditions that often favor formation of products with high degree of crystallinity [35]. This is further supported by the fact that $\mathrm{Sr}^{2+}$ bearing $\mathrm{HA}$ is much more soluble than pure HA, so its precipitation is not thermodynamically favored [59].

\subsection{Understanding $\mathrm{Sr}^{2+}$ incorporation and its impact on biomimetic HA local order}

To gain further insight into $\mathrm{Sr}^{2+}$ incorporation into HA in terms of $\mathrm{Ca}^{2+}$ substitution versus surface adsorption, ${ }^{1} \mathrm{H}$ and ${ }^{31} \mathrm{P}$ solid state NMR were performed to probe the local environment of phosphates. Sharp resonance peaks centered around $3 \mathrm{ppm}$, which are characteristic of $\mathrm{PO}_{4}^{3-}$ ions in crystalline $\mathrm{HA}$, are found in the quantitative ${ }^{31} \mathrm{P}$ MAS NMR spectra for the series of samples $0-25 \% \mathrm{Sr}^{2+}$ (Fig. 4a). Increasing $\mathrm{Sr}^{2+}$ content broadens the resonance signal and shifts it toward downfield (Table S2). These findings show that $\mathrm{Ca}^{2+}$ substitution for $\mathrm{Sr}^{2+}$ in the HA lattice increases the distribution of environments around the phosphates, thereby confirming the structural disorder induced by $\mathrm{Sr}^{2+}$. Such strains in the HA crystalline lattice could also influence bond lengths and angles of the phosphate changing its chemical environment [60]. The pronounced broadening observed for the $25 \% \mathrm{Sr}^{2+}$ sample could also result from the presence of amorphous particles, as discussed above. A similar behavior was observed in the ${ }^{31} \mathrm{P}$ NMR spectra of $\mathrm{Mg}^{2+}$-substituted $\mathrm{HA}$, which was also related to structural disorder caused by the ionic substitution [61]. The $50 \% \mathrm{Sr}^{2+}$ and $75 \% \mathrm{Sr}^{2+}$ samples exhibit broad signals (Fig. $4 \mathrm{a}$ ) characterized by Gaussian line shapes with typical line widths (LW) values of amorphous phosphate environments $(\sim 630 \mathrm{~Hz})$ (Table S2). This result once again confirms that the increase of $\mathrm{Sr}^{2+}$ concentration leads to the disruption of the apatitic environment and gives place to a large distribution of chemical environments.

To obtain further information about $\mathrm{Sr}^{2+}$ distribution in the HA particles surface and core, $2 \mathrm{D}^{1} \mathrm{H}^{31} \mathrm{P}$ HetCor spectra were recorded (Fig. $4 \mathrm{~b}-\mathrm{d}$ ). The $2 \mathrm{D}^{1} \mathrm{H}^{3}{ }^{31} \mathrm{P}$ HetCor spectra of the $5 \% \mathrm{Sr}^{2+}$ and $10 \% \mathrm{Sr}^{2+}$ samples are depicted in Fig. S8. This experiment allows the correlation of phosphate and proton chemical environments leading to the identification of possible local structural differences in the samples. The $0 \% \mathrm{Sr}^{2+}$ and $25 \% \mathrm{Sr}^{2+}$ samples exhibit two cross peaks $\left(\delta\left({ }^{31} \mathrm{P}\right) \sim 3 \mathrm{ppm}\right)$ revealing two distinct chemical environments: one related to the apatitic $\mathrm{PO}_{4}^{3-}$ (correlation with $\mathrm{OH}^{-}$ions $(\delta$ $\left.\left({ }^{1} \mathrm{H}\right)=0 \mathrm{ppm}\right)$, and another correlated with water $\left(\delta\left({ }^{1} \mathrm{H}\right)=5 \mathrm{ppm}\right)$ and $\mathrm{HPO}_{4}^{2-}\left(\delta\left({ }^{1} \mathrm{H}\right)=12.5 \mathrm{ppm}\right)$ on the HA surface (Fig. $4 \mathrm{~b}, \mathrm{c}$ ). The low content of strontium in samples $0-25 \mathrm{Sr}^{2+}$ precipitate under the form of spherulites, which consist of core-layer nanoplatelets. Such core-layer organization (crystalline $v s$ amorphous) is characteristic of biomimetic apatite [28]. In the $25 \% \mathrm{Sr}^{2+}$ sample, micrometric amorphous material is revealed by TEM but its NMR signal cannot be distinguished from the one of the HA particles (i.e. amorphous layer).

The ${ }^{31} \mathrm{P}$ slices extracted from each correlation peak revealed a sharper resonance typical of crystalline apatite $\left(\delta\left({ }^{31} \mathrm{P}\right) \sim 3.0 \mathrm{ppm}\right.$ and LW $\sim 150 \mathrm{~Hz}$ ) and a broad resonance characteristic of amorphous phosphate $\left(\delta\left({ }^{31} \mathrm{P}\right) \sim 3.2 \mathrm{ppm}\right.$ and $\left.\mathrm{LW} \sim 500 \mathrm{~Hz}\right)$. These features characteristic of biomimetic apatite, thereby highlight the great potential of this model to investigate $\mathrm{Sr}^{2+}$ incorporation in bone. Indeed, the proposed mechanism for $\mathrm{Sr}^{2+}$ incorporation in bone involves two steps: first, the $\mathrm{Sr}^{2+}$ ions are weakly and reversibly adsorbed on the apatite hydrated amorphous layer. Then, they are subsequently incorporated into the crystalline lattice by substituting $\mathrm{Ca}^{2+}$ positions typically at a maximum of $10 \%$, whereas excess $\mathrm{Sr}^{2+}$ accumulates on the bone surface $[62,8]$. The ${ }^{31} \mathrm{P}$ projections of the crystalline core and hydrated disordered layer reveal that the LW values increase progressively with $\mathrm{Sr}^{2+}$ concentration in the crystalline core and in the hydrated layer (Table 2), thereby confirming $\mathrm{Sr}^{2+}$ incorporation in both HA sites.

In order to gain insight into the protons chemical environments, double $\mathrm{CP}{ }^{1} \mathrm{H} \rightarrow{ }^{31} \mathrm{P} \rightarrow{ }^{1} \mathrm{H}$ MAS NMR spectra were recorded for the series of samples $0-25 \% \mathrm{Sr}^{2+}$ (Fig. S9). The spectra exhibit a narrow and intense peak around $0 \mathrm{ppm}$, which is characteristic of $\mathrm{OH}^{-}$ions in the crystalline apatitic environment, and two peaks, at 5.5 and $15 \mathrm{ppm}$, corresponding to adsorbed water and $\mathrm{HPO}_{4}^{2-}$, respectively. The position of the $\mathrm{OH}^{-}$peak does not change with $\mathrm{Ca}^{2+}$ substitution for $\mathrm{Sr}^{2+}$ in HA. Nevertheless, such peak broadened slightly with $\mathrm{Sr}^{2+}$ addition suggesting that the distribution of chemical environments around the hydroxyl groups increased. Interestingly, compared to $\mathrm{OH}^{-}$, the relative intensity of the $\mathrm{H}_{2} \mathrm{O}$ and $\mathrm{HPO}_{4}^{2-}$ resonance peaks increase upon $\mathrm{Sr}^{2+}$ addition, suggesting the augment in the ratio of HA hydrated layer and crystalline core.

The $2 \mathrm{D}{ }^{1} \mathrm{H}^{31} \mathrm{P}$ HetCor MAS NMR spectrum of the $75 \% \mathrm{Sr}^{2+}$ sample (Fig. 4d) shows typical signatures of amorphous phosphate: a broad signal in the $\delta\left({ }^{1} \mathrm{H}\right)$ range of $\sim 5-15 \mathrm{ppm}$, corresponding to water and $\mathrm{HPO}_{4}^{2-}$. The absence of cross peak related to $\mathrm{OH}^{-}$ions 
(a)

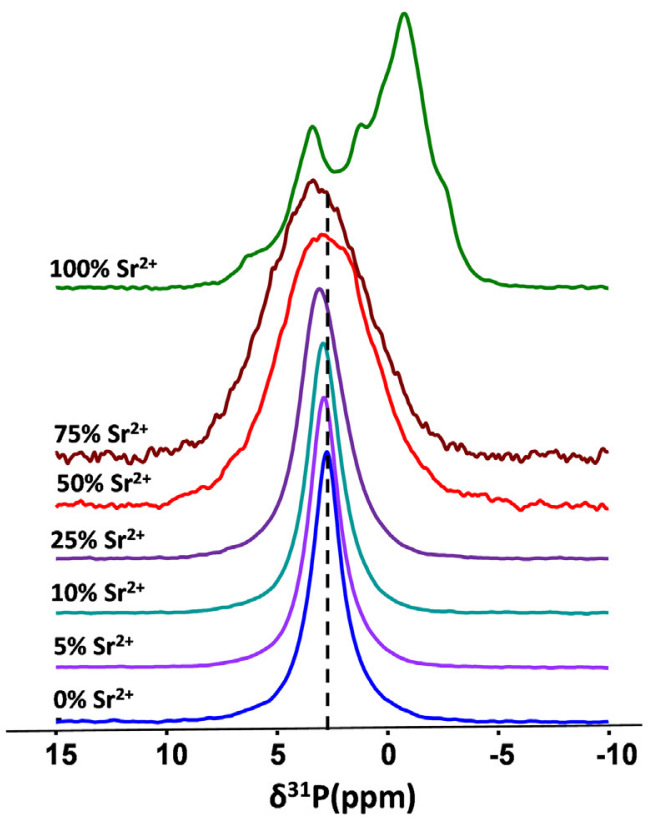

(b)

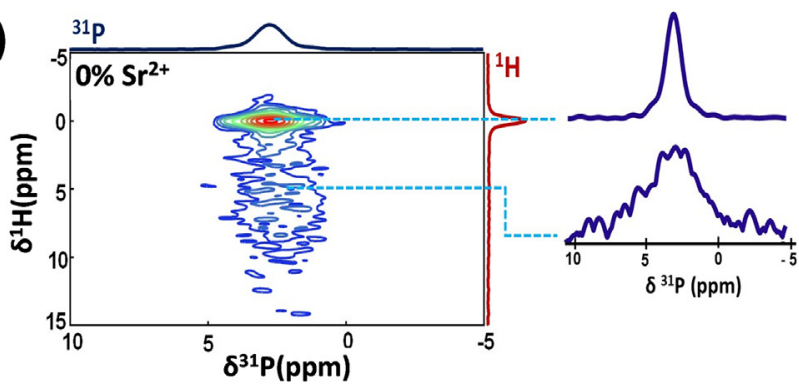

(c)

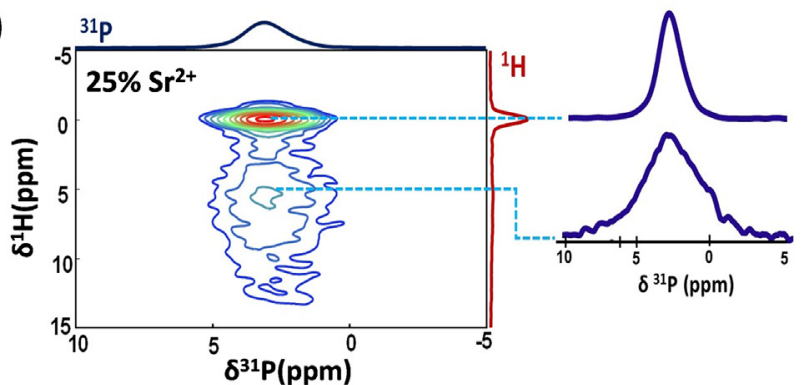

(d)

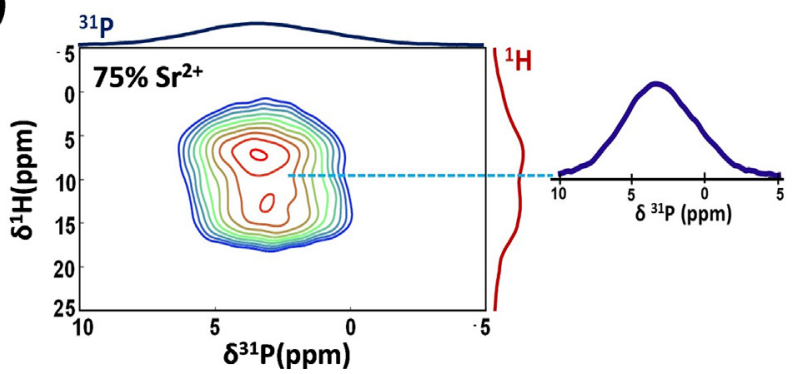

Fig. 4. (a) ${ }^{31} \mathrm{PMAS}$ spectra of the series of samples $0-100 \% \mathrm{Sr}^{2+}$ after six days of reaction (b-d) ${ }^{1} \mathrm{H}^{31} \mathrm{P}$ HetCor spectra of the $0 \% \mathrm{Sr}^{2+}, 25 \% \mathrm{Sr}^{2+}$ and $75 \% \mathrm{Sr}^{2+}$ samples and extracted ${ }^{31} \mathrm{P}$ slices corresponding to the resonance at $\delta\left({ }^{1} \mathrm{H}\right)=0$ and $4.85 \mathrm{ppm}$ due to the apatitic core and the hydrated disordered layer domains, respectively.

confirms that this amorphous phase is homogeneous. These results support the currently accepted mechanism for $\mathrm{Sr}^{2+}$ incorporation into bone in terms of localization in different regions (surface and crystalline lattice) $[63,64]$ and limited ratio of $\mathrm{Ca}^{2+}$ replacement with $\mathrm{Sr}^{2+}$ in biological apatite $[6,14]$.

\subsection{Understanding $\mathrm{Sr}^{2+}$ distribution between crystalline and amorphous phases}

Shorter experiments (one day) were conducted to investigate the $\mathrm{Sr}^{2+}$ effects on amorphous particle formation. Spheres with rough surfaces and diameters of several micrometers are observed in the SEM images for the $50 \% \mathrm{Sr}^{2+}$ and $75 \% \mathrm{Sr}^{2+}$ samples (Fig. $5 \mathrm{a}, \mathrm{e}$ ). Remarkably, the $50 \% \mathrm{Sr}^{2+}$ sample has rougher spheres as compared to the $75 \% \mathrm{Sr}^{2+}$ sample. Further TEM investigation was performed revealing the presence of two dominant structures in both systems: <100 nm homogeneous spheres with smooth surface (Fig. 5c, g) and dense, bigger particles with needles emanating from the surface (Fig. 5b, f), which are less frequent in the $75 \% \mathrm{Sr}^{2+}$ sample and agreed with the SEM observations.

Although XRD confirms the formation of an amorphous phase, SAED patterns taken from the surface of the $50 \% \mathrm{Sr}^{2+}$ sample exhibit narrow rings (Fig. 5d, inset) revealing the presence of crystalline domains. In contrast, the inner part of the sphere displays broad diffraction rings (Fig. 5b, inset) confirming its amorphous nature. Similar investigations were performed on the $75 \% \mathrm{Sr}^{2+}$ sample and found that both the core and surface are characterized by diffraction patterns with broad rings (Fig. 5f, h, inset), confirming the absence of crystalline domains in contrast to the $50 \% \mathrm{Sr}^{2+}$ sample. The smaller smooth spheres present in both systems display SAED patterns with broad rings. Diffraction fringes are absent in the HRTEM images, which is typical of amorphous materials (Fig. $5 \mathrm{~g}$, inset). The presence of crystalline domains on the surface of the $50 \% \mathrm{Sr}^{2+}$ amorphous particles suggests that the $\mathrm{Sr}^{2+}$ content in the starting solutions plays a role in the dynamics of ion exchange between the particle surface and the reaction medium. At $50 \% \mathrm{Sr}^{2+}$, more $\mathrm{Ca}^{2+}$ ions can accumulate on the particle surface as compared to the $75 \% \mathrm{Sr}^{2+}$ sample, thus favoring local HA precipitation.

To gain further insights into $\mathrm{Sr}^{2+}$ distribution in $\mathrm{HA}$ and $\mathrm{Sr}(\mathrm{ACP})$ and into their mechanism of formation, the $25 \% \mathrm{Sr}^{2+}$ system (characterized as a mixture of both structures) was studied by STEMEELS. Such technique allows the acquisition of spatially resolved mappings that show the elemental distribution. This is an important starting point to obtain a link between the different structures found in this system and $\mathrm{Sr}^{2+}$ incorporation. EELS spectra were obtained for HA and $\mathrm{Sr}(\mathrm{ACP}$ ) particles (Fig. 6). The spectra were collected for an energy range spanning from 300 to $2500 \mathrm{eV}$, enabling a simultaneous measurement of Ca-L (346 eV), O-K (530 eV), Sr-L $(1940 \mathrm{eV})$, and P-K $(2146 \mathrm{eV})$. Comparison between the spectra of both particles shows that the main difference is the weaker $\mathrm{Ca}$ peak for the amorphous phase. On the other hand, both phases exhibit Sr-L and P-K edges with similar intensities (Fig. 6, inset). Quantifications based on calculated EELS X-section result in approximate $\mathrm{Sr} / \mathrm{Ca}$ ratios of $\mathrm{ca} .0 .16$ for the $\mathrm{Sr}^{2+}$ substituted HA and of $c a .0 .27$ for the $\operatorname{Sr}(\mathrm{ACP})$. These results confirm that the amorphous phase has a much higher $\% \mathrm{Sr}^{2+}$ than the apatitic phase.

STEM-EELS with nanometric resolution was performed on the amorphous particles containing crystalline needles (Fig. 7). The EELS spectra recorded from 100 to $700 \mathrm{eV}$ and comprising the P-L (132 eV), Sr-M (133 eV), C-K (285 eV), Ca-L (346 eV), and O-K $(530 \mathrm{eV})$ edges can be seen for the inner part of the amorphous particle and the outer layer. EELS mapping also evidences that the outer needles and amorphous core have different calcium compositions. On the basis of EELS and SAED, the needles correspond to $\mathrm{Sr}^{2+}$-substituted HA precipitated at the surface of the amorphous phase. This confirms our hypothesis that $\mathrm{Ca}^{2+}$ accumulates on the surface of the amorphous phase by ion exchange with the reaction medium. 
Table 2

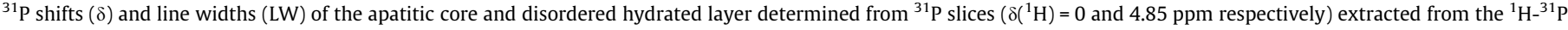
HetCor spectra of the 6 days samples.

\begin{tabular}{|c|c|c|c|c|}
\hline \multirow[t]{2}{*}{ Sample } & \multicolumn{2}{|l|}{${ }^{31} \mathrm{P}$ apatitic core } & \multicolumn{2}{|c|}{${ }^{31} \mathrm{P}$ amorphous layer } \\
\hline & $\delta\left({ }^{31} \mathrm{P}\right) \pm 0.05 \mathrm{ppm}$ & $\mathrm{LW} \pm 10 \mathrm{~Hz}$ & $\delta\left({ }^{31} \mathrm{P}\right) \pm 0.05 \mathrm{ppm}$ & $\mathrm{LW} \pm 10 \mathrm{~Hz}$ \\
\hline $0 \% \mathrm{Sr}^{2+}$ & 2.71 & 153 & 2.52 & 415 \\
\hline $5 \% \mathrm{Sr}^{2+}$ & 2.81 & 170 & 2.61 & 472 \\
\hline $10 \% \mathrm{Sr}^{2+}$ & 2.87 & 180 & 2.72 & 485 \\
\hline $25 \% \mathrm{Sr}^{2+}$ & 3.06 & 238 & 2.91 & 527 \\
\hline $75 \% \mathrm{Sr}^{2+}$ & - & - & 3.33 & 699 \\
\hline
\end{tabular}
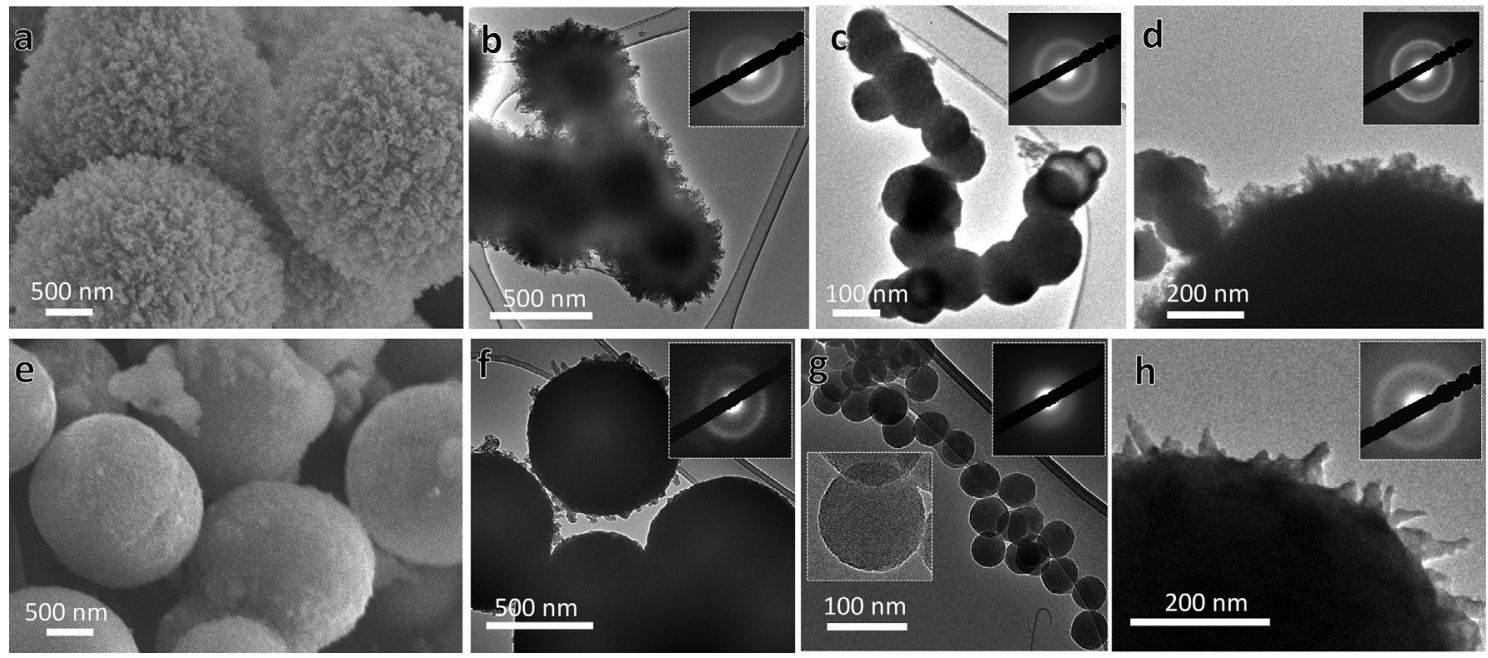

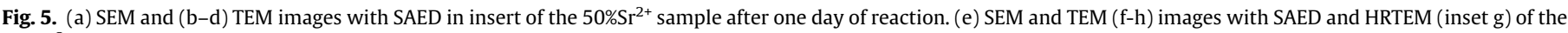
$75 \% \mathrm{Sr}^{2+}$ sample after one day of reaction.

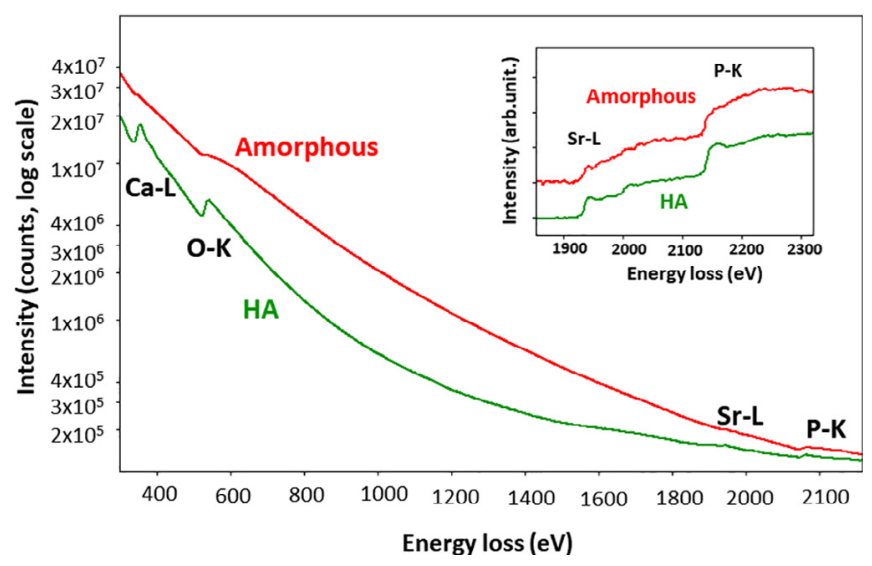

Fig. 6. EELS spectra of the $\mathrm{Sr}^{2+}$-doped $\mathrm{HA}$ and $\mathrm{Sr}(\mathrm{ACP})$ present in the $25 \% \mathrm{Sr}^{2+}$ sample after one day of reaction (300-2500 eV energy range and 1900-2300 eV energy range in the inset).

\subsection{The impact of $\mathrm{Sr}^{2+}$ on the pathway of HA mineralization}

Herein, the approach adopted to synthesize HA avoided precipitation of other phases like octacalcium phosphate, brushite and amorphous calcium phosphate by using acidic $\mathrm{pH}$ (3.5) at the start of the reaction and slow crystallization rate through $\mathrm{NH}_{3(\mathrm{~g})}$ diffusion. As shown by XRD, solid state NMR and TEM, HA and $\mathrm{Sr}^{2+}$-only substituted HA was found in the series of samples $0-10 \% \mathrm{Sr}^{2+}$, whereas a small amount of amorphous particles start to precipitate in the $25 \% \mathrm{Sr}^{2+}$ sample as evidenced by TEM. These findings indicate an amorphous phase-mediated pathway in HA precipitation. $\mathrm{Sr}^{2+}$ progressively stabilizes this amorphous precur- sor and, at higher $\mathrm{Sr}^{2+}$ incorporation $\left(50 \% \mathrm{Sr}^{2+}\right.$ and $\left.75 \% \mathrm{Sr}^{2+}\right)$, its conversion into HA did not occur even after six days of reaction. As shown before, incorporation of $\mathrm{Sr}^{2+}$ elicits structural strains in HA thereby limiting its amount into the HA hexagonal structure. On the other hand, amorphous structures have high ability to accommodate ions and molecules. Indeed, enhanced $\mathrm{Sr}^{2+}$ uptake in calcite via an amorphous precursor pathway has been demonstrated [65]. Recently, the synergic effect of $\mathrm{Sr}^{2+}$ and $\mathrm{Mg}^{2+}$ on amorphous calcium phosphate stabilization [66] has been reported and shown to retard its conversion into HA. In the present study, $\operatorname{Sr}(\mathrm{ACP})$ particles originated in the absence of additives. This was different from the amorphous particles currently described as transient phases, which are rapidly converted into HA [67]. Here, the $\mathrm{Sr}$ (ACP) persisted in the reaction medium suggesting its high stability. Amorphous phases are ubiquitous in nature. They occur in carbonate silicates and phosphate biominerals and play a pivotal role in biomineralization [68]. Even though the Ostwald rule of stages predicts that metastable amorphous phases are typically converted into the most thermodynamically stable polymorphs [69], amorphous precursors can be kinetically or thermodynamically stabilized by using organic additives, confined volumes [70], and trace elements [71] such as $\mathrm{Mg}^{2+}$ [72] and also $\mathrm{Sr}^{2+}$, as shown here. Recently, it was shown that $\mathrm{Mg}^{2+}$ is heterogeneously distributed in the bone tissue; it accumulates in the boundary regions of human enamel in the form of $\mathrm{Mg}^{2+}$ bearing amorphous calcium phosphate [73]. The formation of highly stable Sr(ACP) under physiological conditions suggests that $\mathrm{Sr}^{2+}$ may also be heterogeneously distributed in bone within regions of low structural order. In addition to the structural incompatibility between $\mathrm{HA}$ and high $\mathrm{Sr}^{2+}$ concentrations, the surface energy effect must be considered [74].

Particle size and hydration are key parameters to understand the thermodynamic stability of polymorphs and their occurrence in natural systems $[75,76]$. An increase in surface area can lead 


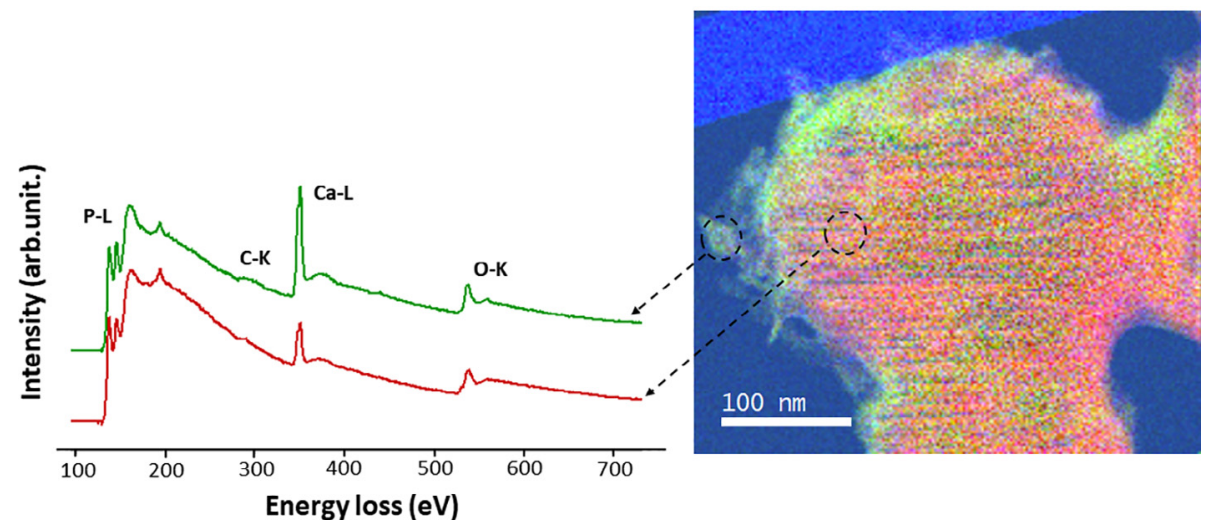

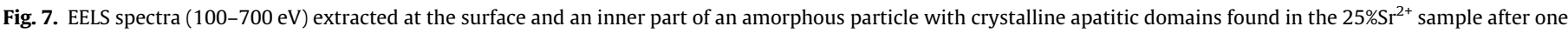
day of reaction. The image is composed by the intensity of the P-L (red), the C-K (blue), and the Ca-L (green) edges.

to kinetically stabilized polymorphs instead of the thermodynamic products usually obtained at ambient conditions. As a result, complex crossovers of polymorphs are observed at the nanoscale [77]. In fact, by means of calorimetric experiments it was demonstrated that particles with larger surface area allow hydrated phases to exist as a consequence of the decrease in surface energy due to water adsorption [78]. In this sense, the presence of totally amorphous nanometric particles (as shown by TEM, SAED, and HRTEM) strongly suggests additional stabilization of the $\operatorname{Sr}(\mathrm{ACP})$ particles by surface energy and formation of bigger particles most probably by coalescence and attachment of smaller particle.

\section{Conclusions}

Overall, the co-existence of $\mathrm{Sr}^{2+}$ substituted $\mathrm{HA}$ and $\mathrm{Sr}(\mathrm{ACP})$ is described which questions the limit of $\mathrm{Sr}^{2+}$ solubility into HA under biomimetic conditions. Moreover, at specific concentration, $\mathrm{Sr}^{2+}$ can effectively stabilize ACP, similarly to another important stabilizing agent of amorphous precursors such as $\mathrm{Mg}^{2+}$. These intriguing results suggest that heterogeneous $\mathrm{Sr}^{2+}$ distribution in bone may be associated with regions of low structural order.

In general terms, by setting biomimetic conditions, this study provides physicochemical understanding of the $\mathrm{Sr}^{2+}$ effect on HA mineralization and substantial insights into its impact on the bone tissue. Additionally, the presented model is comprehensive and can be adopted to describe the effect of other ions and molecules of biological interest in the bone mineralization pathway. Further investigations dedicated to the $\mathrm{Sr}^{2+}$ impact on 3D collagen matrices should provide new input to understand the stability of amorphous Sr-Ca phosphate phase in bone environment.

\section{Declaration of Competing Interest}

None.

\section{Acknowledgments}

Camila B. Tovani thanks São Paulo Research Foundation (FAPESP- grants 2014/24249-0 and 2017/24827-2) for the scholarships. Ana P. Ramos thanks FAPESP (grant 2017/08892-9) for financial support. Nadine Nassif thanks Fondation College de France and Fondation EDF for financial support. The authors also acknowledge Dr. Jean-Marc Krafft from LRS (SU) for assistance with Raman experiments, Laurence Bonnet-Lericque for insightful discussions about Sr-based medicine and Dr. Cynthia Maria de Campos Prado Manso for reviewing the text.

\section{Appendix A. Supplementary data}

Supplementary data to this article can be found online at https://doi.org/10.1016/j.actbio.2019.05.036.

\section{References}

[1] D. Taylor, J.G. Hazenberg, T.C. Lee, Living with cracks: damage and repair in human bone, Nat. Mater. 6 (2007) 263-268.

[2] D.J. Hadjidakis, I.I. Androulakis, Bone remodeling, Ann. N. Y. Acad. Sci. 1092 (2006) 385-396.

[3] G.R. Mundy, Cytokines and growth factors in the regulation of bone remodeling, J. Bone Miner. Res. 8 (Suppl 2) (1993) S505-S510.

[4] L.D. Quarles, Cation sensing receptors in bone: a novel paradigm for regulating bone remodeling?, J Bone Miner. Res. 12 (1997) 1971-1974.

[5] E. Bonnelye, A. Chabadel, F. Saltel, P. Jurdic, Dual effect of strontium ranelate: stimulation of osteoblast differentiation and inhibition of osteoclast formation and resorption in vitro, Bone 42 (2008) 129-138.

[6] S.G. Dahl, P. Allain, P.J. Marie, Y. Mauras, G. Boivin, P. Ammann, Y. Tsouderos, P. D. Delmas, C. Christiansen, Incorporation and distribution of strontium in bone, Bone 28 (2001) 446-453.

[7] W.E. Cabrera, I. Schrooten, M.E. De Broe, P.C. D’haese, Rev. Strontium Bone 14 (1999) 661-668.

[8] G. Boivin, P. Deloffre, B. Perrat, G. Panczer, M. Boudeulle, Y. Mauras, P. Allain, Y Tsouderos, P.J. Meunier, Strontium distribution and interactions with bone mineral in monkey iliac bone after strontium salt (S 12911) administration, J. Bone Miner. Res. 11 (2009) 1302-1311.

[9] N. Allison, A.A. Finch, S.R. Sutton, M. Newville, Strontium heterogeneity and speciation in coral aragonite: implications for the strontium paleothermometer, Geochim. Cosmochim. Acta. 65 (2001) 2669-2676.

[10] C.B. Tovani, T.M. Oliveira, A. Gloter, A.P. Ramos, $\mathrm{Sr}^{2+}$-substituted $\mathrm{CaCO}_{3}$ nanorods: impact on the structure and bioactivity, Cryst. Growth Des. 18 (2018) 2932-2940.

[11] P. Habibovic, J.E. Barralet, Bioinorganics and biomaterials: Bone repair, Acta Biomater. 7 (2011) 3013-3026.

[12] J.Y. Reginster, E. Seeman, M.C. De Vernejoul, S. Adami, J. Compston, C. Phenekos, J.P. Devogelaer, M.D. Curiel, A. Sawicki, S. Goemaere, O.H. Sorensen, D. Felsenberg, P.J. Meunier, Strontium ranelate reduces the risk of nonvertebral fractures in postmenopausal women with osteoporosis: treatment of peripheral osteoporosis (TROPOS) study, J. Clin. Endocrinol. Metab. 90 (2005) 2816-2822.

[13] E. Seeman, B. Vellas, C. Benhamou, J.P. Aquino, J. Semler, J.M. Kaufman, K. Hoszowski, A.R. Varela, C. Fiore, K. Brixen, J.Y. Reginster, S. Boonen, Strontium ranelate reduces the risk of vertebral and nonvertebral fractures in women eighty years of age and older, J. Bone Miner. Res. 21 (2006) 1113-1119.

[14] G. Boivin, D. Farlay, M.T. Khebbab, X. Jaurand, P.D. Delmas, P.J. Meunier, In osteoporotic women treated with strontium ranelate, strontium is located in bone formed during treatment with a maintained degree of mineralization, Osteoporos. Int. 21 (2010) 667-677.

[15] E. Gentleman, Y.C. Fredholm, G. Jell, N. Lotfibakhshaiesh, M.D. O’Donnell, R.G. Hill, M.M. Stevens, The effects of strontium-substituted bioactive glasses on osteoblasts and osteoclasts in vitro, Biomaterials 31 (2010) 3949-3956.

[16] Á.J. Leite, A.I. Gonçalves, M.T. Rodrigues, M.E. Gomes, J.F. Mano, Strontiumdoped bioactive glass nanoparticles in osteogenic commitment, ACS Appl. Mater. Interfaces 10 (2018) 23311-23320.

[17] B.L. Riggs, M. LJ, The Worldwide Problem of Osteoporosis : by Epidemiology, Bone. 17 (1995) 505S-511S.

[18] A. Odén, E.V. McCloskey, J.A. Kanis, N.C. Harvey, H. Johansson, Burden of high fracture probability worldwide: secular increases 2010-2040, Osteoporos. Int. 26 (2015) 2243-2248. 
[19] S.C. Verberckmoes, M.E. De Broe, P.C. D’Haese, Dose-dependent effects of strontium on osteoblast function and mineralization, Kidney Int. 64 (2003) 534-543.

[20] I. Schrooten, W. Cabrera, W.G. Goodman, S. Dauwe, L.V. Lamberts, R. Marynissen, W. Dorriné, M.E. De Broe, P.C. D’Haese, Strontium causes osteomalacia in chronic renal failure rats, Kidney Int. 54 (1998) 448-456.

[21] T. Morohashi, T. Sano, S. Yamada, Effects of strontium on calcium metabolism in rats. I. a distinction between the pharmacological and toxic doses, Jpn. J. Pharmacol. 64 (1994) 155-162.

[22] C. Li, O. Paris, S. Siegel, P. Roschger, E.P. Paschalis, K. Klaushofer, P. Fratzl, Strontium is incorporated into mineral crystals only in newly formed bone during strontium ranelate treatment, J. Bone Miner. Res. 25 (2010) 968-975.

[23] M.D. O'Donnell, Y. Fredholm, A. de Rouffignac, R.G. Hill, Structural analysis of a series of strontium-substituted apatites, Acta Biomater. 4 (2008) 1455-1464.

[24] Z.Y. Li, W.M. Lam, C. Yang, B. Xu, G.X. Ni, S.A. Abbah, K.M.C. Cheung, K.D.K. Luk W.W. Lu, Chemical composition, crystal size and lattice structural changes after incorporation of strontium into biomimetic apatite, Biomaterials 28 (2007) 1452-1460.

[25] Z. Geng, Z. Cui, Z. Li, S. Zhu, Y. Liang, W.W. Lu, X. Yang, Synthesis, characterization and the formation mechanism of magnesium- and strontium-substituted hydroxyapatite, J. Mater. Chem. B. 3 (2015) 3738-3746.

[26] J. Terra, E.R. Dourado, J.G. Eon, D.E. Ellis, G. Gonzalez, A.M. Rossi, The structure of strontium-doped hydroxyapatite: an experimental and theoretical study, Phys. Chem. Chem. Phys. 11 (2009) 568-577.

[27] N. Reznikov, M. Bilton, L. Lari, M.M. Stevens, R. Kröger, Fractal-like hierarchical organization of bone begins at the nanoscale, Science 360 (2018).

[28] Y. Wang, S. Von Euw, G. Laurent, C. Crevant, L. Bonhomme-Coury, M.M. Giraud-Guille, F. Babonneau, N. Nassif, T. Azaïs, Impact of collagen confinement vs. ionic substitutions on the local disorder in bone and biomimetic apatites, Mater. Horizons. 1 (2014) 224-231.

[29] R. Astala, M.J. Stott, First principles investigation of mineral component of bone: $\mathrm{CO}_{3}$ substitutions in hydroxyapatite, Chem. Mater. 17 (2005) 4125 4133.

[30] Y. Wang, S. Von Euw, F.M. Fernandes, S. Cassaignon, M. Selmane, G. Laurent, G. Pehau-Arnaudet, C. Coelho, L. Bonhomme-Coury, M.M. Giraud-Guille, F. Babonneau, T. Azaiis, N. Nassif, Water-mediated structuring of bone apatite, Nat. Mater. 12 (2013) 1144-1153.

[31] N. Nassif, F. Martineau, O. Syzgantseva, F. Gobeaux, M. Willinger, T. Coradin, S. Cassaignon, T. Azaïs, M.M. Giraud-Guille, In vivo inspired conditions to synthesize biomimetic hydroxyapatite, Chem. Mater. 22 (2010) 3653-3663.

[32] Y. Wu, J.L. Ackerman, D.A. Chesler, L. Graham, Y. Wang, M.J. Glimcher, Density of organic matrix of native mineralized bone measured by water- and fatsuppressed proton projection MRI, Magn. Reson. Med. 50 (2003) 59-68.

[33] G.H. An, H.J. Wang, B.H. Kim, Y.G. Jeong, Y.H. Choa, Fabrication and characterization of a hydroxyapatite nanopowder by ultrasonic spray pyrolysis with salt-assisted decomposition, Mater. Sci. Eng. A. 449-451 (2007) 821-824.

[34] J. Liu, K. Li, H. Wang, M. Zhu, H. Xu, H. Yan, Self-assembly of hydroxyapatite nanostructures by microwave irradiation, Nanotechnology 16 (2005) 82-87.

[35] H.S. Gupta, F. Guitia, An effective morphology control of hydroxyapatite crystal via hydrothermal synthesis, Cryst. Growth Des. 9 (2009) 466-474.

[36] K.C.B. Yeong, J. Wang, S.C. Ng, Mechanochemical synthesis of nanocrystalline hydroxyapatite from $\mathrm{CaO}$ and $\mathrm{CaHPO}_{4}$, Biomaterials 22 (2001) 2705-2712.

[37] S. Bose, S.K. Saha, Synthesis and Characterization of Hydroxyapatite Nanopowders by Emulsion Technique, Chem. Mater. 15 (2003) 4464-4469.

[38] M. Uota, H. Arakawa, N. Kitamura, T. Yoshimura, J. Tanaka, T. Kijima Encapsulées dans stéarate de calcium synthesis of high surface area hydroxyapatite nanoparticles by mixed surfactant-mediated approach, Langmuir 21 (2005) 4724-4728.

[39] A. Bigi, E. Boanini, C. Capuccini, M. Gazzano, Strontium-substituted hydroxyapatite nanocrystals, Inorganica Chim. Acta. 360 (2007) 1009-1016.

[40] A. Akiva, M. Kerschnitzki, I. Pinkas, W. Wagermaier, K. Yaniv, P. Fratzl, L. Addadi, S. Weiner, Mineral formation in the larval zebrafish tail bone occurs via an acidic disordered calcium phosphate phase, J. Am. Chem. Soc. 138 (2016) 14481-14487.

[41] N. Folliet, C. Roiland, S. Bégu, A. Aubert, T. Mineva, A. Goursot, K. Selvaraj, L. Duma, F. Tielens, F. Mauri, G. Laurent, C. Bonhomme, C. Gervais, F. Babonneau, T. Azaiis, Investigation of the interface in silica-encapsulated liposomes by combining solid state NMR and first principles calculations, J. Am. Chem. Soc. 133 (2011) 16815-16827.

[42] R. Baron, L. Neff, D. Louvard, P.J. Courtoy, Acidification and bone cell-mediated extracellular evidence for a low pH in resorbing lacunae resorption : of a 100kD Lysosomal Membrane Protein and Localization at the Osteoclast Ruffled Border, J. Cell Biol. 101 (1985) 2210-2222.

[43] W. Querido, A.P.C. Campos, E.H. Martins Ferreira, R.A.S. San Gil, A.M. Rossi, M. Farina, Strontium ranelate changes the composition and crystal structure of the biological bone-like apatite produced in osteoblast cell cultures, Cell Tissue Res. 357 (2014) 793-801.

[44] S.C. Verberckmoes, G.J. Behets, L. Oste, A.R. Bervoets, L.V. Lamberts, M. Drakopoulos, A. Somogyi, P. Cool, W. Dorriné, M.E. De Broe, P.C. D'Haese, Effects of strontium on the physicochemical characteristics of hydroxyapatite, Calcif. Tissue Int. 75 (2004) 405-415.

[45] R.K. Fuchs, M.R. Allen, K.W. Condon, S. Reinwald, L.M. Miller, D. McClenathan, B. Keck, R.J. Phipps, D.B. Burr, Strontium ranelate does not stimulate bone formation in ovariectomized rats, Osteoporos. Int. 19 (2008) 1331-1341.
[46] E.P. Paschalis, F. Betts, E. DiCarlo, R. Mendelsohn, A.L. Boskey, FTIR microspectroscopic analysis of human iliac crest biopsies from untreated osteoporotic bone, Calcif. Tissue Int. 61 (1997) 487-492.

[47] E.P. Paschalis, P. Fratzl, S. Gamsjaeger, N. Hassler, W. Brozek, E.F. Eriksen, F. Rauch, F.H. Glorieux, E. Shane, D. Dempster, A. Cohen, R. Recker, K. Klaushofer, Aging versus postmenopausal osteoporosis: bone composition and maturation kinetics at actively-forming trabecular surfaces of female subjects aged 1 to 84 years, J. Bone Miner. Res. 31 (2016) 347-357.

[48] S. Koutsopoulos, Synthesis and characterization of hydroxyapatite crystals: a review study on the analytical methods, J. Biomed. Mater. Res. 62 (2002)600-612.

[49] N.S. Chickerur, M.S. Tung, W.E. Brown, A mechanism for incorporation of carbonate into apatite, Calcif. Tissue Int. 32 (1980) 55-62.

[50] M.E. Fleet, Infrared spectra of carbonate apatites: v2-Region bands, Biomaterials 30 (2009) 1473-1481.

[51] A. Antonakos, E. Liarokapis, T. Leventouri, Micro-Raman and FTIR studies of synthetic and natural apatites, Biomaterials 28 (2007) 3043-3054.

[52] C. Rey, V. Renugopalakrishnan, B. Collins, M.J. Glimcher, Fourier transform infrared spectroscopic study of the carbonate ions in bone mineral during aging, Calcif. Tissue Int. 49 (1991) 251-258.

[53] Y. Wang, T. Azaïs, M. Robin, A. Vallée, C. Catania, P. Legriel, G. Pehau-Arnaudet, F. Babonneau, M.M. Giraud-Guille, N. Nassif, The predominant role of collagen in the nucleation, growth, structure and orientation of bone apatite, Nat. Mater. 11 (2012) 724-733.

[54] D. Farlay, G. Boivin, G. Panczer, A. Lalande, P.J. Meunier, Long-term strontium ranelate administration in monkeys preserves characteristics of bone mineral crystals and degree of mineralization of bone, J. Bone Miner. Res. 20 (2005) $1569-1578$.

[55] L. Oste, A.R. Bervoets, G.J. Behets, G. Dams, R.L. Marijnissen, H. Geryl, L.V. Lamberts, S.C. Verberckmoes, V.O. Van Hoof, M.E. De Broe, P.C. D’Haese, Timeevolution and reversibility of strontium-induced osteomalacia in chronic renal failure rats, Kidney Int. 67 (2005) 920-930.

[56] P.C. D’Haese, I. Schrooten, W.G. Goodman, W.E. Cabrera, L.V. Lamberts, M.M. Elseviers, M.M. Couttenye, M.E. De Broe, Increased bone strontium levels in hemodialysis patients with osteomalacia, Kidney Int. 57 (2000) 1107-1114.

[57] J.F.H. Jokes, The metabolism of calcium and phosphorus as influenced by the addition to the diet of salts of metals which form insoluble phosphate, Am. J. Physiol. (1938) 230-237.

[58] G. Bechkoff, J. Radisson, L. Bessueille, K. Bouchekioua-Bouzaghou, R. Buchet, Distinct actions of strontium on mineral formation in matrix vesicles, Biochem. Biophys. Res. Commun. 373 (2008) 378-381.

[59] H.B. Pan, Z.Y. Li, W.M. Lam, J.C. Wong, B.W. Darvell, K.D.K. Luk, W.W. Lu, Solubility of strontium-substituted apatite by solid titration, Acta Biomater. 5 (2009) 1678-1685.

[60] B.R. Brooks, C.L. Brooks, III, J.A.D. Mackerell, L. Nilsson, R.J. Petrella, B. Roux, Y. Won, G. Archontis, C. Bartels, S. Boresch, A. Caflisch, L. Caves, Q. Cui, A.R. Dinner, M. Feig, S. Fischer, J. Gao, M.W.I. Hodoscek, M. Karplus, CHARMM: The biomolecular simulation program B, J. Comput. Chem. 30 (2009) 1545-1614.

[61] D. Laurencin, N. Almora-Barrios, N.H. de Leeuw, C. Gervais, C. Bonhomme, F. Mauri, W. Chrzanowski, J.C. Knowles, R.J. Newport, A. Wong, Z. Gan, M.E. Smith, Magnesium incorporation into hydroxyapatite, Biomaterials 32 (2011) 1826-1837.

[62] D. Bazin, A. Dessombz, C. Nguyen, H.K. Ea, F. Lioté, J. Rehr, C. Chappard, S. Rouzière, D. Thiaudière, S. Reguer, M. Daudon, The status of strontium in biological apatites: An XANES/EXAFS investigation, J. Synchrotron Radiat. 21 (2014) 136-142.

[63] G. Boivin, P.J. Meunier, The mineralization of bone tissue: a forgotten dimension in osteoporosis research, Osteoporos. Int. 14 (2016) 19-24.

[64] P.J. Marie, P. Ammann, G. Boivin, C. Rey, Mechanisms of action and therapeutic potential of strontium in bone, Calcif. Tissue Int. 69 (2001) 121-129.

[65] J.L. Littlewood, S. Shaw, C.L. Peacock, P. Bots, D. Trivedi, I.T. Burke, Mechanism of Enhanced Strontium Uptake into Calcite via an Amorphous Calcium Carbonate Crystallization Pathway, Cryst. Growth Des. 17 (2017) 1214-1223.

[66] T.G. Kim, B. Park, Synthesis and growth mechanisms of one-dimensional strontium hydroxyapatite nanostructures, Inorg. Chem. 44 (2005) 9895-9901.

[67] T.H. Zhang, X.Y. Liu, How Does a Transient Amorphous Precursor, Template.pdf (2007) 13520-13526.

[68] L.B. Gower, Biomimetic model systems for investigating the amorphous precursor pathway and its role in biomineralization, Chem. Rev. 108 (2008) $4551-4627$.

[69] S.Y. Chung, Y.M. Kim, J.G. Kim, Y.J. Kim, Multiphase transformation and Ostwalds rule of stages during crystallization ofametal phosphate, Nat. Phys. 5 (2009) 68-73.

[70] L. Addadi, S. Raz, S. Weiner, Taking advantage of disorder: Amorphous calcium carbonate and its roles in biomineralization, Adv. Mater. 15 (2003) 959-970.

[71] M.L. Whittaker, W. Sun, K.A. Derocher, S. Jayaraman, G. Ceder, D. Joester, Structural basis for metastability in amorphous calcium barium carbonate (ACBC), Adv. Funct. Mater. 28 (2018) 1704202.

[72] Z. Zou, W.J.E.M. Habraken, G. Matveeva, A.C.S. Jensen, L. Bertinetti, M.A. Hood, C. Sun, P.U.P.A. Gilbert, I. Polishchuk, B. Pokroy, J. Mahamid, Y. Politi, S. Weiner, P. Werner, S. Bette, R. Dinnebier, U. Kolb, E. Zolotoyabko, P. Fratzl, A hydrated crystalline calcium carbonate phase: Calcium carbonate hemihydrate, Science 363 (2019) 396-400.

[73] A. La Fontaine, A. Zavgorodniy, H. Liu, R. Zheng, M. Swain, J. Cairney, Atomicscale compositional mapping reveals $\mathrm{Mg}$-rich amorphous calcium phosphate in human dental enamel, Sci. Adv. 2 (2016). 
[74] A. Navrotsky, L. Mazeina, J. Majzlan, Size-driven structural and thermodynamic complexity in iron oxides, Science 319 (2008) 1635-1638.

[75] A. Navrotsky, Energetic clues to pathways to biomineralization: Precursors, clusters, and nanoparticles, Proc. Natl. Acad. Sci. 101 (2004) 12096-12101.

[76] J.J. De Yoreo, P.U.P.A. Gilbert, N.A.J.M. Sommerdijk, R.L. Penn, S. Whitelam, D. Joester, H. Zhang, J.D. Rimer, A. Navrotsky, J.F. Banfield, A.F. Wallace, F.M. Michel, F.C. Meldrum, H. Cölfen, P.M. Dove, Crystallization by particle attachment in synthetic, biogenic, and geologic environments, Science 349 (2015) aaa6760.

[77] A. Navrotsky, Nanoscale effects on thermodynamics and phase equilibria in oxide systems, ChemPhysChem 12 (2011) 2207-2215.

[78] J.M. Mchale, A Auroux, A.J. Perrotta, A Navrotsky, Surface energies and thermodynamic phase surface energies and thermodynamic phase stability in nanocrystalline aluminas, Science 277 (1997) 788-791. 